\title{
Incentive Learning Underlying Cocaine-Seeking Requires mGluR5 Receptors Located on Dopamine D1 Receptor-Expressing Neurons
}

\author{
Martin Novak, ${ }^{1 \star}$ Briac Halbout, ${ }^{2 *}$ Eoin C. 0'Connor, ${ }^{3 *}$ Jan Rodriguez Parkitna, ${ }^{1}$ Tian Su, ${ }^{1}$ Minqiang Chai, ${ }^{1}$ \\ Hans S. Crombag, ${ }^{3}$ Ainhoa Bilbao, ${ }^{2}$ Rainer Spanagel, ${ }^{2}$ David N. Stephens, ${ }^{3}$ Günther Schütz, ${ }^{1}$ and David Engblom ${ }^{1,4}$ \\ ${ }^{1}$ Molecular Biology of the Cell I, German Cancer Research Center, 69120 Heidelberg, Germany, ${ }^{2}$ Department of Psychopharmacology, Central Institute of \\ Mental Health, J5, 68159 Mannheim, Germany, ${ }^{3}$ School of Psychology, University of Sussex, Brighton, BN1 9QG, United Kingdom, and ${ }^{4}$ Department of \\ Clinical and Experimental Medicine, Linköping University, 58185, Linköping, Sweden
}

Understanding the psychobiological basis of relapse remains a challenge in developing therapies for drug addiction. Relapse in cocaine addiction often occurs following exposure to environmental stimuli previously associated with drug taking. The metabotropic glutamate receptor, mGluR5, is potentially important in this respect; it plays a central role in several forms of striatal synaptic plasticity proposed to underpin associative learning and memory processes that enable drug-paired stimuli to acquire incentive motivational properties and trigger relapse. Using cell type-specific RNA interference, we have generated a novel mouse line with a selective knock-down of mGluR5 in dopamine D1 receptor-expressing neurons. Although mutant mice self-administer cocaine, we show that reinstatement of cocaineseeking induced by a cocaine-paired stimulus is impaired. By examining different aspects of associative learning in the mutant mice, we identify deficits in specific incentive learning processes that enable a reward-paired stimulus to directly reinforce behavior and to become attractive, thus eliciting approach toward it. Our findings show that glutamate signaling through mGluR5 located on dopamine D1 receptor-expressing neurons is necessary for incentive learning processes that contribute to cue-induced reinstatement of cocaineseeking and which may underpin relapse in drug addiction.

\section{Introduction}

The most challenging feature of cocaine addiction is the high risk of relapse even after long periods of abstinence. A common trigger of relapse in vulnerable individuals is exposure to environmental stimuli previously associated with drug use (Stewart et al., 1984). The enduring control over relapse by cocaine-paired stimuli reflects the ability of addictive drugs to hijack neural substrates of associative reward-learning and memory that normally

\footnotetext{
Received May 5, 2010; revised June 29, 2010; accepted July 15, 2010.
}

This work was supported by the Deutsche Forschungsgemeinschaft through Collaborative Research Centers SFB 488 and SFB 636, by the Fonds der Chemischen Industrie, the European Union through Grant LSHM-CT-2005-018652 (CRESCENDO), the Bundesministerium für Bildung und Forschung through NGFNplus Grants FZK 01 GS08153 and 01GS08142, the Helmholtz Gemeinschaft Deutscher Forschungszentren through Initiative CoReNe and Alliance HeIMA, and the Deutsche Krebshilfe through project 108567. D.E. was supported by the Swedish Research Council, the Thuring, Wiberg and Jeansson foundations and the Swedish Society of Medicine. E.C.O. receives a studentship from the Biotechnology and Biological Sciences Research Council and Pfizer Inc. Research in D.N.S.'s laboratory is supported by the United Kingdom Medical Research Council. H.S.C. was supported by a Marie Curie reintegration award. We thank Ali Nasr Esfahani for help with immunohistochemistry, Milen Kirilov and Daniel Habermehl for input on short RNAs, and Witold Konopka for valuable suggestions.

*M.N., B.H., and E.C.O. contributed equally to the work.

Correspondence should be addressed to either of the following: David Engblom, Department of Clinical and Experimental Medicine, Linköping University, 58185, Linköping, Sweden, E-mail: david.engblom@liu.se; David N. Stephens, School of Psychology, University of Sussex, Brighton BN1 9QG, UK, E-mail: d.stephens@sussex.ac.uk; or Rainer Spanagel, Department of Psychopharmacology, Central Institute of Mental Health, J5, 68159 Mannheim, Germany, E-mail: rainer.spanagel@zi-mannheim.de.

J. Rodriguez Parkitna's present address: Department of Molecular Neuropharmacology, Institute of Pharmacology of the Polish Academy of Sciences, 31-343 Cracow, Poland.

DOI:10.1523/JNEUROSCI.2550-10.2010

Copyright $\odot 2010$ the authors $\quad$ 0270-6474/10/3011973-10\$15.00/0 enable environmental stimuli paired with natural rewards (e.g., food or water) to guide adaptive behaviors (Robinson and Berridge, 1993; Berke and Hyman, 2000; Kauer and Malenka, 2007). However, associative reward-learning can be dissociated into a variety of psychologically and neurobiologically distinct processes (Everitt et al., 2001). Consequently, understanding the psychobiological basis of relapse is of considerable importance for developing effective treatments for cocaine addiction.

A common neuronal substrate of associative reward-learning processes involves striatal medium spiny neurons (MSNs), which integrate mesostriatal dopaminergic signals and glutamatergic inputs arising from cortical and limbic regions (Kauer and Malenka, 2007; Goto and Grace, 2008). MSNs provide the sole striatal output to motivational and motor systems and can be divided into two functionally distinct populations, expressing either dopamine D1 (D1-MSNs) or D2 (D2-MSNs) receptors (Gerfen et al., 1990; Heiman et al., 2008; Valjent et al., 2009). However, the relative contributions of D1- and D2-MSNs to motivational output and the molecular events in MSNs underpinning associative reward-learning processes that contribute to relapse-like behaviors remain elusive.

The metabotropic glutamate receptor, mGluR5, is particularly interesting in this context. It is involved in several forms of plasticity in striatal MSNs that are proposed to mediate associative learning and memory processes (Sung et al., 2001; Gubellini et al., 2003; Malenka and Bear, 2004; Hyman et al., 2006; Schotanus and Chergui, 2008), and which are affected by cocaine expe- 
rience (Martin et al., 2006; Kauer and Malenka, 2007; Kourrich et al., 2007; Bellone et al., 2008; Anwyl, 2009; Moussawi et al., 2009). Although mGluR5 is densely expressed on both D1- and D2MSN populations (Tallaksen-Greene et al., 1998), converging lines of research would suggest that mGluR5 located specifically on D1-MSNs is ideally positioned to influence associative reward-learning processes that may underpin relapse triggered by drug-paired stimuli. First, there is evidence that striatal dopamine D1 receptors (D1R) play a critical role in both the consolidation of associative reward-learning memories (Dalley et al., 2005) and many of the long-term effects of addictive drugs (Anderson and Pierce, 2005) and second, mGluR5 appears to interact closely with D1Rs to regulate striatal neurotransmission (Paolillo et al., 1998; Voulalas et al., 2005; Schotanus and Chergui, 2008).

Here, we determine the role of mGluR5 located on dopamine D1 receptor (D1R)-expressing neurons, in behaviors influenced by drug- or natural reward-paired stimuli, by generation of a novel mouse line in which mGluR5 is selectively knocked-down in neurons expressing the D1R. These mice reveal a necessary role of mGluR5 located on D1R-expressing neurons for highly specific associative reward-learning processes underlying cueinduced reinstatement of cocaine-seeking.

\section{Materials and Methods}

\section{Mouse generation}

Short hairpin RNAs were designed using the sFold (sTarMir) and BLOCK-IT RNAi Designer (Invitrogen) software packages and tested in cell culture for knock-down (KD) efficiency of mGluR5 mRNA. BLOCK-iT Pol II miR RNAi Expression vector kit with GW/EmGFPmiR vector (Invitrogen) was used to insert synthetic oligos to artificial miRNA context (Fig. $1 B$ ). The construct was recombined into a bacterial artificial chromosome (BAC; RP24-179E13; Children's Hospital Oakland Research Institute, Oakland, CA) harboring the mouse D1R gene following a procedure previously described (Parkitna et al., 2009) (Fig. $1 A)$. The $\mathrm{BAC}$ was purified, the vector sequences were removed, and the transgene was injected into the pronuclei of fertilized oocytes from C57BL/6N mice. Experimental animals were generated by backcrossing of mGluR5 ${ }^{\mathrm{KD}-\mathrm{D} 1}$ transgenic mice to $\mathrm{C} 57 \mathrm{BL} / 6 \mathrm{~N}$ line. Transgenic animals were genotyped using the following primers: ACGTAAACGGCCACAAGTTC, AAGTCGTGCTGCTTCATGTG. Food and water were provided ad libitum. KD and wild-type (WT) littermates 8-20 weeks of age were used for the neurobiological characterization of the transgenic lines.

\section{In Situ hybridization}

An 900-bp-long digoxigenin (DIG)-labeled riboprobe was used for mGluR5 mRNA detection. The DNA template was synthesized using the primers: ACCCCTATCTGCTCTTCCTACC and GTCTACTGAATGGAGGGACCAG. Probe was generated using a DIG RNA Labeling Kit (SP6/T7) from Roche. Brains were fixed in $4 \%$ paraformaldehyde at $4^{\circ} \mathrm{C}$ for $48 \mathrm{~h}$ and $50 \mu \mathrm{m}$ free-floating vibratome sections were hybridized with the DIG-labeled probe at $70^{\circ} \mathrm{C}$ overnight. Signal was developed using alkaline phosphatase-conjugated antigen binding fragments and 5-bromo-4-chloro-3'-indolylphosphate $p$-toluidine salt and nitroblue tetrazolium chloride as a substrate (Roche).

\section{Quantitative PCR}

RNA was isolated (RNeasy Mini Kit, QIAGEN) from striata fixed in RNAlater solution (Ambion) at $4^{\circ} \mathrm{C}$ overnight. cDNA was synthesized using $250 \mathrm{ng}$ of total RNA as template and oligo-dT reversetranscription primer (TaqMan Reverse Transcription Reagents, Applied Biosystems). The quantity of specific transcripts was measured using the TaqMan gene expression assays against mGluR5 (Mm01317988_m1), Hprt1 (Mm01545399_m1), Gfap (Mm00546086_m1) and a custom assay for EmGFP. The quantification of mature microRNAs in the striatum was performed on samples containing only small RNAs ( $<200 \mathrm{nt})$ isolated using mirVana miRNA Isolation Kit (Ambion, catalog \#AM1561).
Removal of ribosomal RNA was verified on RNA LabChips. Small RNAs were detected by quantitative PCR using MicroRNA Reverse Transcription kit (Applied Biosystems) and microRNA detection assays: mmumiR-9 (part\#4373371), hsa-miR-15a (4373123), hsa-miR-16 (4373121), mmu-miR-124a (4373150), hsa-miR-138 (4373175), snoRNA-234 (4380915) on $10 \mathrm{ng}$ of the small RNA sample.

\section{Immunohistochemistry and immunofluorescence}

Immunohistochemistry with anti-GFP antibody (1:10 000, Invitrogen, A11122, Lot 50434A) was performed using avidin-biotin-peroxidase complex (ABC) amplification and diaminodbenzidine as a substrate. For immunofluorescence we used: rabbit anti-GFP (1:1000, Invitrogen, see above), donkey anti-rabbit Alexa Fluor 488 (1:100, Invitrogen, A21206), chicken anti-GFP (1:1000, Abcam, ab13970), donkey anti-chicken Alexa Fluor 488, rabbit anti-prepro enkephalin (Neuromics, RA15125), goat anti-rabbit Alexa Fluor 568, mouse anti-DARPP-32 (BD Transduction Laboratories, 611520), mouse anti-NeuN (1:400, Millipore Bioscience Research Reagents, MAB377, Lot 0604027006), Cy5-conjugated antimouse (Jackson ImmunoResearch), chicken anti-mouse Alexa Fluor 594 (1:100, Invitrogen, A21201). Image analyses were performed with the Image (v1.37, Wayne Rasband, National Institutes of Health, Bethesda, MD) and Creative Suite CS4 (Adobe) software. GFP and NeuN-positive cells were counted on 8 consecutive striatal sections per animal.

\section{Immunoblotting}

Striatal samples were homogenized and denatured at $100^{\circ} \mathrm{C}$ for $10 \mathrm{~min}$. Protein concentration was measured using the bicinchoninic acid (BCA) assay (Sigma-Aldrich). Proteins were detected by rabbit polyclonal antimGluR5 Ab (1:500, Abcam, ab53090). Monoclonal mouse anti-GAPDH $\mathrm{Ab}$ (1:10 000, Millipore, \#MAB374) was used as a loading control. The secondary antibodies used were goat anti-rabbit HRP-linked Ab (1:10 000, Cell Signaling Technology, \#7074) and goat anti-mouse HRPconjugated Ab (1:10 000, Jackson ImmunoResearch, \#115-036-003). The membrane was developed with substrate ECL plus Western Blotting Reagents Mix (GE Healthcare).

\section{Animals for behavioral analysis}

Cocaine studies were conducted in Mannheim, Germany while associative learning studies took place in Brighton, UK. In both laboratories, male WT and KD mice (minimum 8 weeks old) were maintained on a 12-12 h light-dark cycle (with lights on at 7:00 AM) under controlled temperature $\left(21 \pm 2^{\circ} \mathrm{C}\right)$ and humidity $(50 \pm 5 \%)$ conditions. All experiments took place during the light phase. For cocaine studies, mice were single housed and for conditioning studies, mice were single or group housed. For all studies, body weights were maintained at $\sim 85 \%$ of ad libitum feeding weight except for the cocaine self-administration phase during which mice received ad libitum access to food. Experiments were conducted in accordance with European Union guidelines on the care and use of laboratory animals; experiments in Germany were approved by the local animal care committee (Karlsruhe, Germany); experiments in the UK were performed in accordance with the United Kingdom 1986 Animals (Scientific Procedures) Act, following institutional ethical review.

\section{Apparatus for cocaine and associative learning studies}

Behavioral training and testing were performed in mouse conditioning chambers (Med Associates), individually housed within sound and light attenuating cubicles. Each chamber was equipped with a pellet dispenser connected to a recessed food magazine. A retractable lever was located on each side of the magazine and a cue light was positioned above each lever. A tone generator was situated between the cue lights and a house light was positioned on the wall opposite to the food magazine. For the cocaine studies, polyethylene/PVC tubing connected the implanted catheter, via a swivel (Instech Solomon), to an infusion pump (PHM-100, Med Associates) located outside of the cubicle. For the sign-tracking tests, two nose-poke holes, each of which contained a cue-light, were inserted into the conditioning chamber opposite to the food magazine. Conditioning chambers were controlled and responses were recorded using a computer running Med-PC IV (Med Associates). 
A

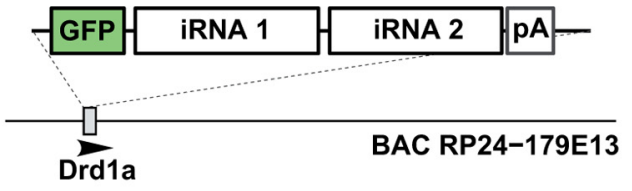

B
$1.4 \mathrm{~kb}$

$195 \mathrm{~kb}$
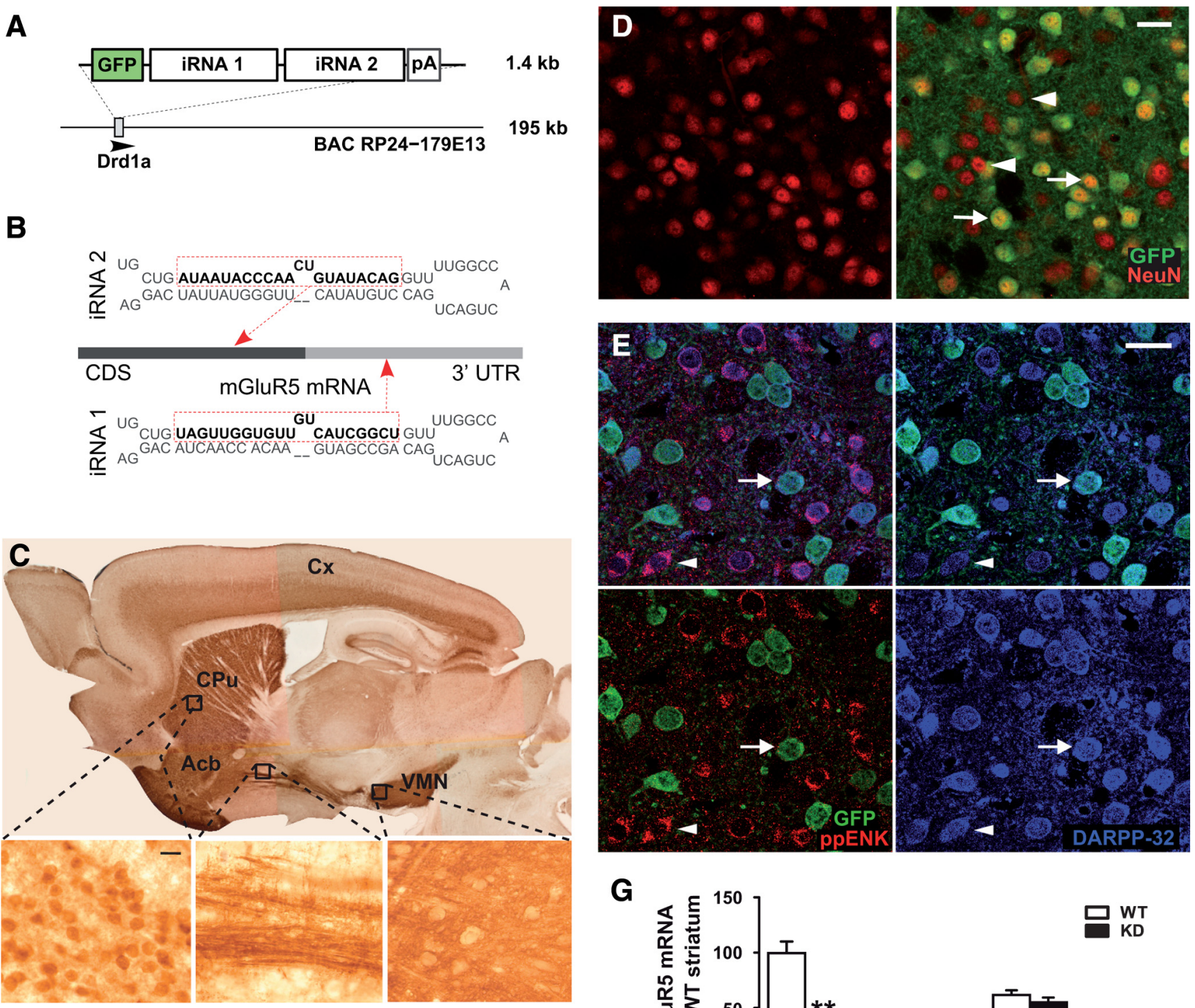

G

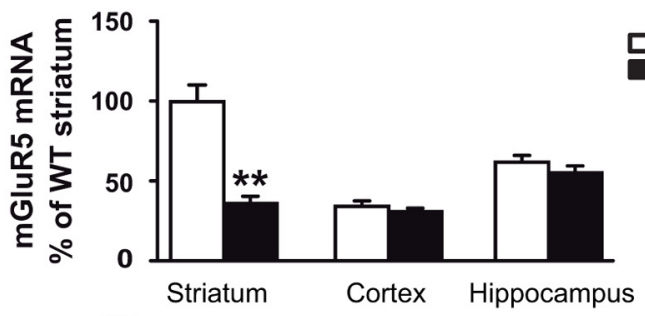

H

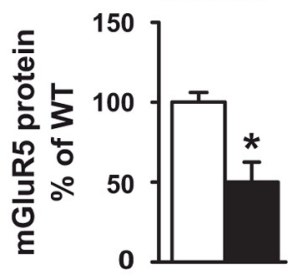

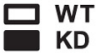

WT
KD

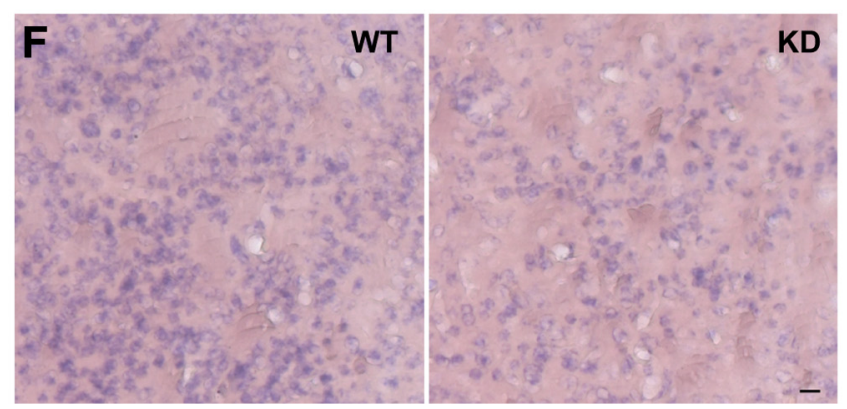

KD

Figure 1. Knock-down of mGluR5 in striatal dopamine receptor D1-MSNs. A, Design of the transgene expressing GFP as a marker and two interfering RNAs (iRNAs). This construct was inserted after the translational start of the gene encoding the dopamine D1 receptor in a bacterial artificial chromosome. $\boldsymbol{B}$, Sequences of iRNAs. Interfering sequence is depicted in bold. Red arrows indicate targeted regions of $\mathrm{mGluR5}$ mRNA. C, Expression of the transgene in $\mathrm{mGluR5}{ }^{\mathrm{KD}-\mathrm{D} 1}$ mice (KD) as detected by immunohistochemistry for GFP in a sagittal brain section. Higher magnification showing difference between staining of cell bodies in the caudate-putamen (CPu) and its projections to ventral midbrain nuclei (VMN). D, The transgene (GFP; green) is expressed in $\sim 53 \%$ of the striatal neurons (NeuN; red; $\rightarrow$ indicates examples of GFP-positive neurons and indicates examples of GFP-negative neurons). $\boldsymbol{E}$, The expression of the construct is selective for D1-MSNs. Thus, expression is limited to MSNs (DARPP-32; blue) and absent from D2-MSNs (labeled by red immunofluorescent labeling of prepro enkephalin; ppEnk). Examples of GFP-expressing ( $\rightarrow$ ) and non-GFP-expressing ( ) MSNs. $\boldsymbol{F}$, Expression of mGluR5 in the striatum as shown with in situ hybridization. $\mathbf{G}$, Knock-down assessment by quantitative $\mathrm{PCR}(n=4-5, p<0.001)$ and $\boldsymbol{H}$, Western-blotting with representative blot example shown $(n=4, p=0.0112)$. Data are presented as mean + SEM, $p$-value of $t$ test $\left({ }^{*} p<0.05,{ }^{* *} p<0.001\right)$. Scale bars $20 \mu$ m. $C x$, Cortex; Acb, nucleus accumbens.

\section{Cocaine studies}

Lever training and surgery. The procedures for lever training, surgery and catheter maintenance were as previously described (Mameli et al., 2009). In brief, to familiarize mice with the action of lever pressing, all mice were trained to lever press for food for a minimum of 14 sessions. The implan- tation of an indwelling catheter in the right jugular vein occurred $24 \mathrm{~h}$ after completion of lever training. Animals were given a minimum of $48 \mathrm{~h}$ recovery before cocaine self-administration sessions began.

Cocaine self-administration. Once-daily, 90 min, self-administration sessions commenced with the insertion of two levers into the condition- 
ing chamber. Responses on one lever (the active lever), under a fixedratio 4 schedule (FR4), resulted in a 14-28 $\mu$ l infusion of cocaine (cocaine hydrochloride; Sigma-Aldrich) delivered by activation of the pump for 1.2-2.4 s. Responses on the alternative lever (the inactive lever) were recorded, but had no scheduled consequence. Each drug infusion was associated with the $20 \mathrm{~s}$ presentation of flashing $(1 \mathrm{~Hz})$ cue lights [conditioned stimulus (CS)], which also signaled a time-out period during which further lever responses were not reinforced.

For dose-response determination, $\mathrm{KD}(n=14)$ and WT $(n=14)$ mice were given access to different cocaine doses $(0.095-1.5 \mathrm{mg} / \mathrm{kg}$ per infusion) in a randomized order during 90 min once daily selfadministration sessions. When self-administration behavior was stable for one dose (three consecutive sessions with $\leq \pm 20 \%$ variation in the number of infusions earned) mice were given access to a different cocaine dose. Data from the third stable session of self-administration, from animals with a patent catheter, were used to generate the dose-response curve.

Cue-induced reinstatement. $\mathrm{KD}(n=7)$ and WT $(n=6)$ mice were trained to self-administer cocaine $(0.75 \mathrm{mg} / \mathrm{kg}$ per infusion $)$ during 10 consecutive sessions under identical conditions to those described above. In addition, 7 animals $(n=4 / 3 ; \mathrm{KD} / \mathrm{WT})$ which received cocaine 0.75 $\mathrm{mg} / \mathrm{kg}$ per infusion as the final dose of the dose-response study were added to this experimental cohort. After the final cocaine selfadministration session, mice received 14, once daily, 90 min extinction sessions in which responses on both levers were recorded but had no scheduled consequence. Prior studies from our laboratory (unpublished) revealed that 14 extinction sessions was sufficient to produce stable lever responding with active lever responses reduced to $50 \%$ or less of responses maintained by cocaine, as well as complete loss of discrimination between the active and inactive levers. Reinstatement tests took place $24 \mathrm{~h}$ after the last extinction session under conditions identical to the final session of cocaine self-administration, except that cocaine was not available. Thus, responses on the previously active lever triggered the noise of the infusion pump and a brief CS presentation. Responses on the inactive lever were without consequence.

\section{Associative learning studies}

Procedure. Mice were assigned to one of three experimental cohorts; one for the assessment of both goal-tracking responses and conditioned reinforcement (CRf), a second for Pavlovian-instrumental transfer (PIT) and a third for sign-tracking. The use of different Pavlovian conditioning procedures for CRf and PIT studies was in recognition of data indicating that these procedures were most suitable for supporting subsequent CRf or PIT behavior (Crombag et al., 2008).

Magazine training. To familiarize mice with the food used for conditioning studies (5TUL, catalog \#1811142; Test Diet), a small amount of the food was given to all mice in their home cage. Mice also received a single, $30 \mathrm{~min}$, magazine training session in which food pellets were delivered once every $60 \mathrm{~s}$, on average (range of 25 to $95 \mathrm{~s}$ ).

Goal-tracking and conditioned reinforcement. The procedures for Pavlovian conditioning, goal-tracking and CRf tests were as previously described (O'Connor et al., 2010). In brief, $\mathrm{KD}(n=12)$ and WT $(n=9)$ mice received 11, once daily, 60 min Pavlovian conditioning sessions in which 16 presentations of a $10 \mathrm{~s}$ stimulus paired with food delivery (CS+; flashing cue lights or constant tone) and 16 presentations of a $10 \mathrm{~s}$ stimulus paired with no outcome (CS-; the alternative stimulus) occurred. Each stimulus trial was separated by a variable, no stimulus, intertrial interval (ITI) [range of $80-120 \mathrm{~s}$; mean $(\mathrm{M})=100 \mathrm{~s}$ ]. Food delivery occurred $5 \mathrm{~s}$ after CS+ onset. Assessment of the acquisition of goaltracking responses was provided by recording food magazine head entries that occurred in the first five seconds following CS + onset (that is, before food delivery). The $45 \mathrm{~min}$ CRf test was undertaken $24 \mathrm{~h}$ after the final conditioning session and commenced with the insertion of two levers into the conditioning chamber. Responses on one lever resulted in brief presentations of the CS + , whereas responses on the alternative lever resulted in brief presentations of the CS-. No food was delivered during the CRf test.

Pavlovian-instrumental transfer. $\mathrm{KD}(n=9)$ and WT $(n=7)$ mice received 12, once daily, 30 min Pavlovian conditioning sessions in which four presentations of a 2 min stimulus paired with food delivery (CS+; an intermittent tone or flashing house light) occurred. Each stimulus event was separated by a variable, no-stimulus, ITI (range of 225-375 s; $\mathrm{M}=300 \mathrm{~s}$ ). Mice then received a further six $45 \mathrm{~min}$ conditioning sessions, in which two presentations of a 2 min stimulus paired with no outcome (CS-; the alternative stimulus) occurred, along with four reinforced presentations of the CS + . The order of stimulus presentations was randomly determined and each stimulus was separated by a variable, no-stimulus, ITI (range of 205-395 s; M = 300 s). Four food pellets were delivered during each CS + presentation. Pellet delivery was equally likely to occur in each $10 \mathrm{~s} \mathrm{time} \mathrm{bin} \mathrm{throughout} \mathrm{the} \mathrm{CS}+$, although a minimum time of $10 \mathrm{~s}$ separated each pellet delivery.

Following Pavlovian conditioning sessions, mice were trained to lever press for food under a variable interval $60 \mathrm{~s}$ schedule (VI60) of reinforcement. Each food self-administration session commenced with the insertion of two levers. Responses on one lever (the active lever) resulted in food delivery, while responses on the alternative lever (the inactive lever) had no scheduled consequence. Instrumental training sessions terminated after 30 food pellets had been obtained, or $30 \mathrm{~min}$ had elapsed.

The PIT test commenced with the insertion of both levers and for the first $5 \mathrm{~min}$, no stimuli were presented. This period was followed by 4 presentations of the $2 \mathrm{~min} \mathrm{CS}+$ and 4 presentations of the 2 min CS-, occurring in an alternating order. Each stimulus presentation was preceded by a $2 \mathrm{~min}$, no-stimulus ITI. No food was delivered during the test. An elevation score was calculated to assess changes in active lever response rate during CS + and CS - presentations (elevation score $=$ lever responses during CS + or CS - presentations minus lever responses during the no-stimulus ITI period before CS + or CS - presentations, respectively).

Sign-tracking. $\operatorname{KD}(n=12)$ and WT $(n=12)$ mice received 11 , once daily, 30 min Pavlovian conditioning sessions in which 16 presentations of a $10 \mathrm{~s}$ stimulus paired with food delivery ( $\mathrm{CS}+$; flashing cue lights) occurred. Each CS+ presentation was separated by a variable, no stimulus, ITI (range of $80-120 \mathrm{~s} ; \mathrm{M}=100 \mathrm{~s}$ ). A single food pellet was delivered $5 \mathrm{~s}$ after CS + onset. For the $45 \mathrm{~min}$ sign-tracking test, conducted $24 \mathrm{~h}$ after the final conditioning session, two nose-poke holes were inserted into the conditioning chamber. In one hole, $15 \times 1$ min presentations of a flashing cue light (that is, the CS + ) occurred. Each CS + presentation was separated by a 2 min no-stimulus ITI. No stimulus presentations occurred in the second (control) nose-poke hole and no food was delivered during the test. Entries into each hole were recorded during CS+ presentations, thus providing a measure of sign-tracking responses (that is, approaches) toward the CS+.

\section{Statistical analysis}

For the assessment of the knock-down efficiency by quantitative PCR and Western blotting, statistical analyses were performed using $t$ test. For cocaine (self-administration and cue-induced reinstatement) and associative learning (goal-tracking, CRf and PIT) studies, data were initially analyzed by mixed-factor ANOVA, where genotype comparisons were represented by the between-subjects factor of genotype (WT, KD). When a significant $(\leq 0.05)$ main effect or interaction term was found, further analysis was performed using ANOVA and post hoc comparisons by Newman-Keuls or $t$ test. For the sign-tracking test, approaches toward the CS+ or a control nose-poke hole were initially compared for each genotype by Mann-Whitney $U$ test, with comparisons of responding in each nose-poke between genotypes made by Wilcoxon matched pairs test.

\section{Results \\ Generation and validation of mice with knock-down of mGluR5 selectively in D1R-expressing neurons}

To test the role of mGluR5 on D1R-expressing neurons we generated mice with a selective knock-down of mGluR5 in these cells (mGluR5 ${ }^{\mathrm{KD}-\mathrm{D} 1}$ mice). We used a construct that expresses two artificial microRNAs targeting mGluR5 mRNA under the control of the D1R promoter (Fig. $1 A, B$ ). The coding sequence for green fluorescent protein (GFP) was introduced in tandem 
A
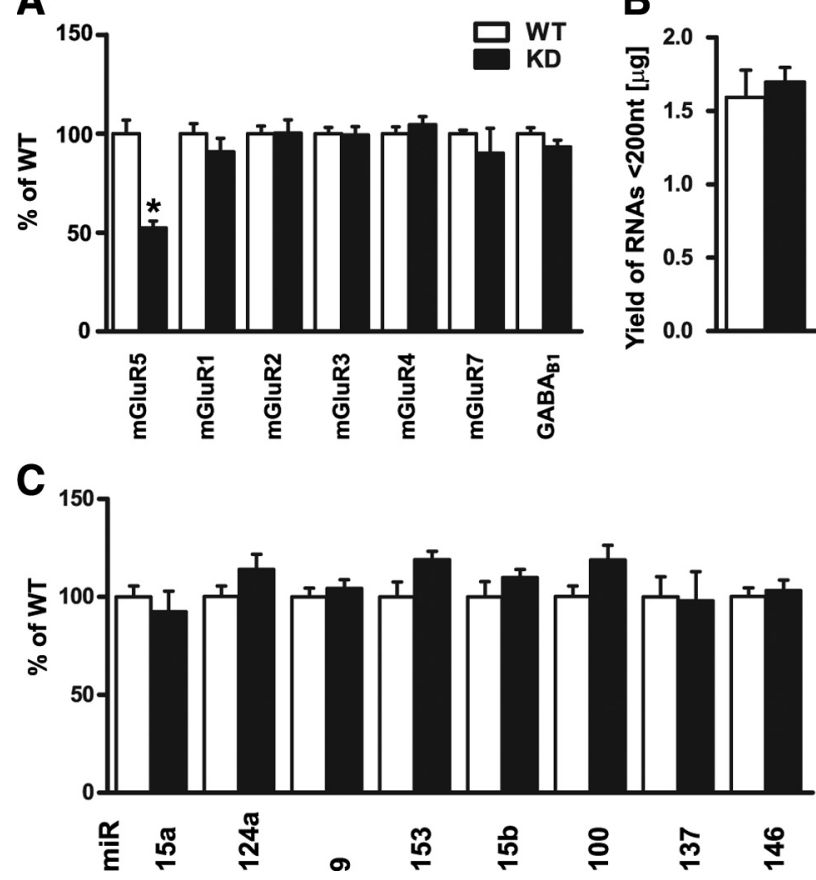

Figure 2. Knock-down of mGluR5 does not interfere with other similar transcripts or with the production of endogenous microRNAs. A, Microarray analysis showing that the transgene did not alter the expression levels of other metabotropic glutamate receptor family members nor the levels of the related $\mathrm{GABA}_{\mathrm{B} 1}$ receptor in $\mathrm{mGluR5} 5^{\mathrm{KD}-\mathrm{D} 1}$ mice (KD). $\boldsymbol{B}$, The yield of small RNAs ( $<200 \mathrm{nt}$ ) isolated from the striatum of transgenic mice was normal. $\boldsymbol{C}$, The abundance of the mature form of eight randomly selected endogenous miRNAs was not altered, indicating an intact microRNA processing machinery. ${ }^{*} p<0.005$.

with the microRNAs (Fig. 1A), enabling us to easily track expression of the construct. Immunostaining of GFP in brains from mGluR5 ${ }^{\text {KD-D1 }}$ mice showed that the expression pattern fits with that described for D1Rs, including strong expression in the dorsal striatum and nucleus accumbens (Fig. 1C). A more detailed examination of the striatum confirmed that the transgene (GFP) was expressed in $\sim 53 \%$ of the striatal neurons (Fig. $1 D$, NeuN). Furthermore, expression of the transgene was confined to MSNs (identified by immunostaining against DARPP-32) (Fig. $1 E$ ) but the transgene was not expressed in D2-MSNs (identified by immunostaining against preproenkephalin; ppEnk) (Fig. 1E), showing that expression is restricted to D1-MSNs. Next, we analyzed whether expression of the transgene reduces the abundance of the mGluR5 transcript. In situ hybridization revealed reduced numbers of mGluR5-positive cells in the striatum, while the staining-intensity in the cells still expressing mGluR5 was not reduced (Fig. $1 F$ ), indicating strong mGluR5 knock-down selectively in the targeted cells. The abundance of mGluR5 transcript was reduced to $\sim 40 \%$ in the homogenized striatum (Fig. $1 G$ ) with the corresponding protein reduced to $\sim 50 \%$ compared with levels in WT mice (Fig. $1 H$ ). Since the expression of the construct is restricted to D1-MSNs (Fig. $1 E$ ), we estimate that the knockdown efficiency is $\sim 90 \%$ in the targeted cells. There was no significant reduction of mGluR 5 mRNA in the cerebral cortex or in the hippocampus of mGluR5 ${ }^{\text {KD-D1 }}$ mice (Fig. $1 G$ ).

Off-target effects (that is, knock-down of mRNAs other than mGluR5) and disruption of endogenous microRNA processing are potential concerns when using interfering RNAs. To exclude the possibility of off-target effects we measured the abundance of transcripts of other mGluR-family members and the related $\mathrm{GABA}_{\mathrm{B} 1}$ receptor (Fig. $2 \mathrm{~A}$ ). In contrast to mGluR5, the abun- dance of the other transcripts was normal. Further, the level of short RNAs in general, as well as the amount of several randomly selected endogenous mature microRNAs, were normal in the striatum of mGluR $5^{\mathrm{KD}-\mathrm{D} 1}$ mice (Fig. $2 \mathrm{~B}$ ) confirming normal function of the endogenous microRNA processing machinery. Together, our data indicate a highly specific and efficient knock-down of mGluR5 mRNA without off-target effects or disruption of endogenous microRNA function.

\section{Cocaine self-administration and cocaine-seeking in} mGluR5 ${ }^{\text {KD-D1 }}$ mice

To explore the consequence of the specific knock-down of mGluR5 for behaviors related to cocaine addiction, we first examined the propensity of mGluR $5^{\mathrm{KD}-\mathrm{D} 1}$ mice to self-administer cocaine. When given access, in a randomized order, to five different doses of cocaine under a fixed-ratio (FR4) schedule of reinforcement, WT and mGluR5 ${ }^{\mathrm{KD}-\mathrm{D} 1}$ mice displayed comparable self-administration behavior (Fig. 3A). Responses on the 'active' lever, which resulted in cocaine infusions and the concomitant presentation of a simple light stimulus, exhibited comparable inverted U-shape curves between genotypes, demonstrating that mGluR5 ${ }^{\mathrm{KD}-\mathrm{D} 1}$ mice were able to adapt their responding to the dose of cocaine available. Moreover, when trained to selfadminister cocaine $(0.75 \mathrm{mg} / \mathrm{kg}$ per infusion $)$ for 10 consecutive sessions, both WT and mGluR5 ${ }^{\mathrm{KD}-\mathrm{D} 1}$ mice rapidly acquired and maintained stable responding on the active lever (Fig. 3B). Collectively, these results indicate that the primary reinforcing effects of cocaine are unaffected by knock-down of mGluR5 on D1Rexpressing cells.

The ability of the stimulus associated with cocaine infusions to reinstate extinguished cocaine-seeking was then assessed. Following stable responding on the active lever during cocaine self-administration sessions, cocaine-seeking responses were extinguished by withholding further drug infusions and stimulus presentations. During extinction sessions, both genotypes significantly reduced responding on the active lever (Fig. $3 C$ ). During the test of cue-induced reinstatement of cocaineseeking, mGluR5 ${ }^{\mathrm{KD}-\mathrm{D} 1}$ mice made significantly fewer responses than WT mice on the active lever that now resulted in presentation of the previously cocaine-paired stimulus, but not cocaine itself (Fig. 3D). These findings indicate that mGluR5 located on D1R-expressing cells is intimately involved in the reinstatement of cocaine-seeking maintained by a cocaine-paired stimulus.

\section{Associative learning in mGluR5 ${ }^{\mathrm{KD}-\mathrm{D} 1}$ mice}

Through associative learning, a stimulus paired with reward (CS) can acquire informative or predictive properties that serve to signal the availability and/or location of the reward (goaltracking) and can also acquire incentive motivational properties enabling CSs to attract attention (sign-tracking), energize ongoing reward-seeking (Pavlovian-instrumental transfer), and/or directly reinforce instrumental behaviors (conditioned reinforcement) (Rescorla, 1988; Robinson and Flagel, 2009). In principle, any of these neurobiologically distinct learned properties could contribute to the effects of drug-paired stimuli on drug-seeking and relapse (Everitt and Robbins, 2005). The next series of experiments examined the consequence of mGluR5 knock-down on D1R-expressing cells for these different aspects of associative reward-learning processes.

Using Pavlovian conditioning procedures, cohorts of hungry mice were presented with a stimulus associated with food delivery $(\mathrm{CS}+)$ and a second stimulus associated with no outcome $(\mathrm{CS}-)$ (conditioning data from conditioned reinforce- 
ment/ goal-tracking cohort shown in Fig. $4 A)$. There was no genotype difference in the learning of predictive properties of the $\mathrm{CS}+$ that enable it to signal the availability and location of reward, as indicated by an increase across conditioning sessions in the number of head-entries into the food-delivery magazine that occurred following onset of the CS+, but before food delivery (goal-tracking responses; Fig. $4 B$ ). mGluR5 ${ }^{\mathrm{KD}-\mathrm{D} 1}$ mice were also able to attribute incentive properties to the CS+ necessary for energizing ongoing reward-seeking, as demonstrated by the ability of noncontingent CS + presentations to enhance responding on a lever previously associated with food delivery (Pavlovian-instrumental transfer test; Fig. 4D).

However, when a CS+ was presented contingent upon a novel instrumental response, mGluR5 ${ }^{\mathrm{KD}-\mathrm{D} 1}$ mice made significantly fewer responses on the lever that resulted in CS+ presentations than WT mice (conditioned reinforcement test; Fig. $4 E)$. In this test, there were no genotype differences in responses on the lever that resulted in CS- presentations, or the latency to explore either lever (lever, genotype, and lever $\times$ genotype interaction, $F<1$ ). The specific impairment in CS+ reinforced lever responding could not be attributed to a general inability of mGluR5 ${ }^{\text {KD-D1 }}$ mice to acquire an instrumental response, because they readily acquired instrumental responding when it was reinforced by the primary food reward (see food self-administration training data from Pavlovian-instrumental transfer cohort, Fig. 4C). Together, these data indicate a necessary role of mGluR5 on D1R-expressing neurons for incentive learning that enables a CS + to serve as a conditioned reinforcer.

Finally, the ability of the CS + to attract behavior was assessed by relocating a discrete light CS+ behind a nose-poke hole and measuring approach responses toward it. mGluR5 ${ }^{\mathrm{KD}-\mathrm{D} 1}$ mice made significantly fewer approaches toward the light CS + than WT mice and there were no significant genotype differences in responses into the control nose-poke hole (sign-tracking test; Fig. $4 F$ ). Thus, in addition to the aforementioned deficit in conditioned reinforcement, mGluR5 knockdown on D1-expressing neurons resulted in a deficit in the attribution of incentive properties to the CS+ necessary for the CS to become highly salient and attractive (Robinson and Berridge, 1993; Tomie et al., 2008).

\section{Discussion}

Using cell type-specific RNA interference, we have generated a novel mouse line in which the metabotropic glutamate receptor, mGluR5, is selectively knocked-down on cells that express dopamine D1 receptors. We identify this mGluR5 population as playing a dissociable role in the primary versus secondary (that is, conditioned) reinforcing effects of cocaine, as revealed by normal cocaine
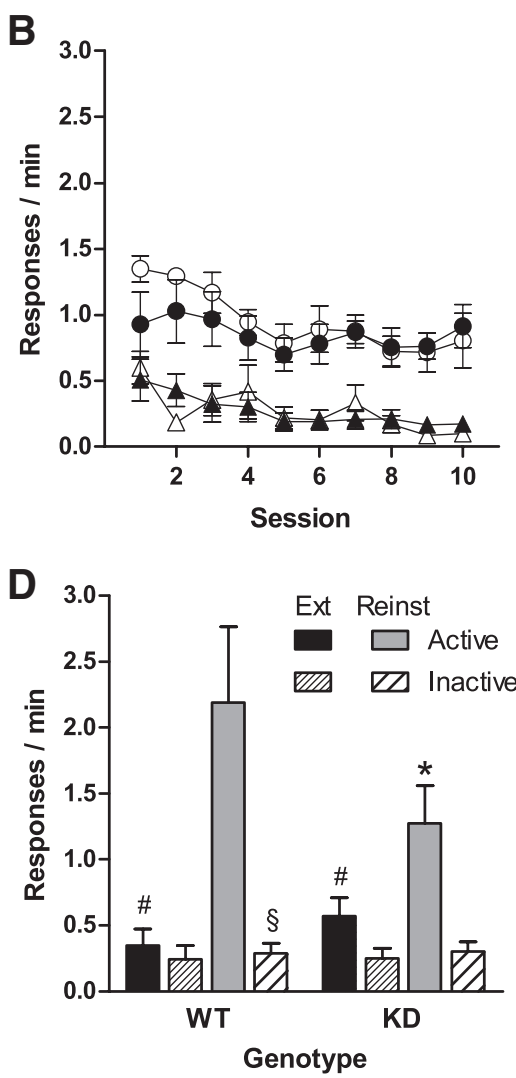

Figure 3. Cocaine self-administration and cue-induced reinstatement in mGluR5 ${ }^{\text {KD-D1 }}$ (KD) and control (WT) mice. Lever-press responses during cocaine self-administration $(\boldsymbol{A}, \boldsymbol{B})$, extinction $(\boldsymbol{C})$, and cue-induced reinstatement test phases $(\boldsymbol{D})$. $\boldsymbol{A}$, Self-administration: cocaine-reinforced $(\mathbf{O}$, active) and nonreinforced $(\boldsymbol{\Delta}$, inactive) responses across five different doses of cocaine did not 0 consecutive sessions with a $0.75 \mathrm{mg} / \mathrm{kg}$ per infusion training dose did not significantly differ between WT and KD mice ion $\times$ lever $\times$ genotype, $\left.F_{(9,198)}=1.56 ; p>0.05\right)$. During the training phase, the presentation of a (S was associated with and 14 subsequent extinction sessions did not differ between the two genotypes (session $\times$ genotype, $F_{(16,288)}=1.27 ; p>0.05$ ). D, Reinstatement: lever responses during the last extinction session (Ext) and the cue-induced reinstatement test (Reinst). Contingent presentation of the $C S$ increased the number of responses on the active lever over extinction performance, in mice from both genotypes. However, reinstatement of the cocaine-seeking response was significantly lower in KD mice (genotype $X$ lever $X$

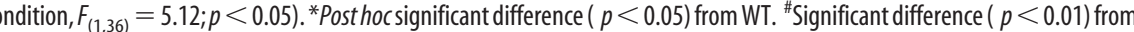
the active lever responses during extinction. SSignificant difference $(p<0.01)$ from active lever responses during reinstatement. Responses are plotted as mean ( \pm SEM).

self-administration but impaired cue-induced reinstatement of cocaine-seeking in mGluR5 ${ }^{\mathrm{KD}-\mathrm{D} 1}$ mice. A detailed assessment of reward-learning in these mice reveals specific deficits in learning processes necessary for the attribution of incentive motivational properties to reward-paired stimuli that enable them to directly reinforce behaviors (conditioned reinforcement) and to become highly salient and attractive (sign-tracking). However, other aspects of reward learning were normal in mutant mice, including learning about the predictive properties of reward-paired stimuli which serve to signal the availability and location of reward (goal-tracking) and incentive learning that enables the reward-paired stimulus to energize responding directed toward obtaining a reward (Pavlovianinstrumental transfer). Collectively, our data indicate that mGluR5 located on D1R-expressing neurons play a central role in specific associative reward-learning processes, which are engaged following cocaine experience and thereby enable environmental stimuli associated with cocaine to exert a prolonged and pervasive influence over relapse susceptibility.

To interfere with the expression of mGluR5 selectively in D1R-expressing neurons we used a BAC-based construct in 

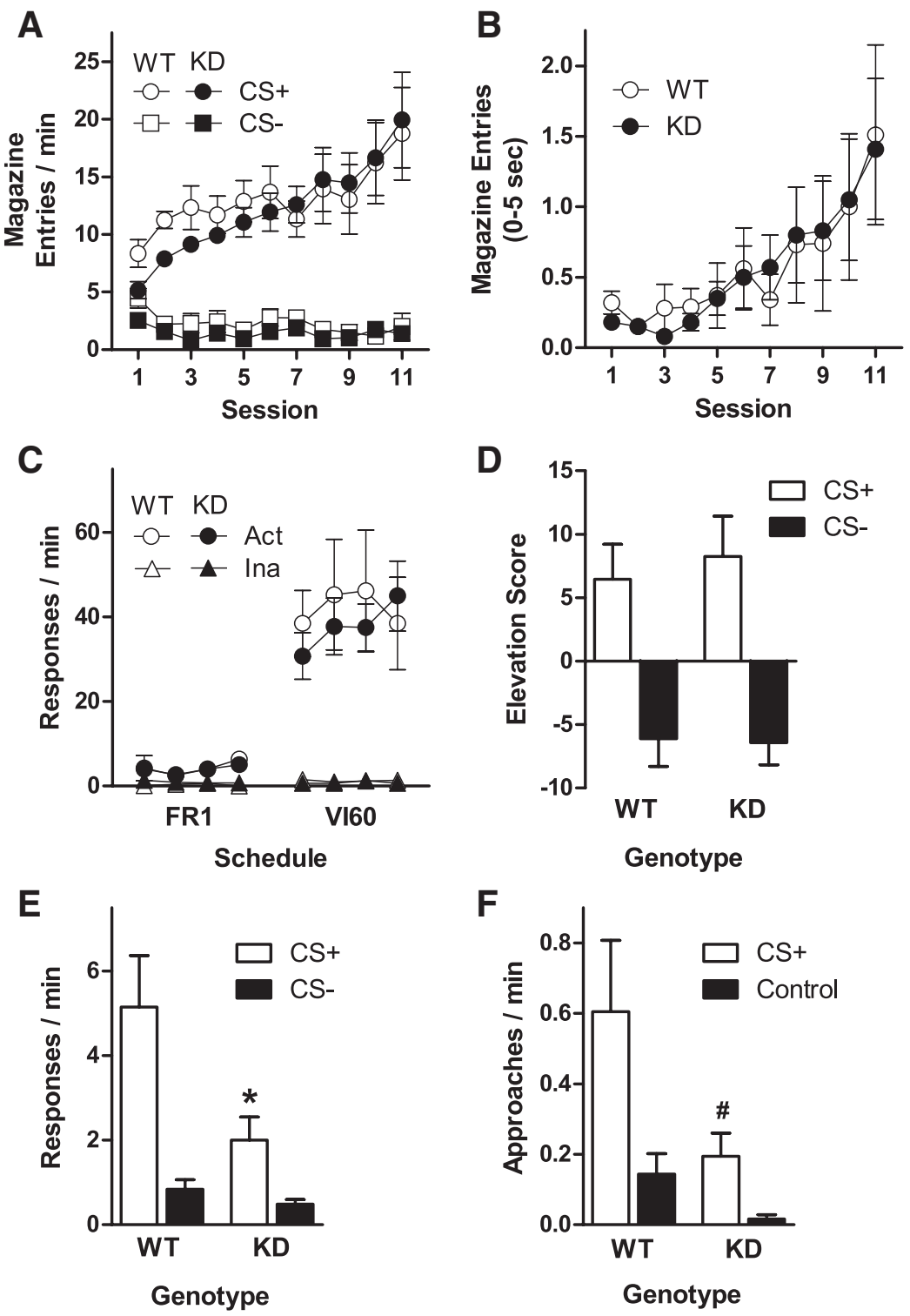

Figure 4. Associative learning in mGluR5 ${ }^{\mathrm{KD}-\mathrm{D} 1}$ (KD) and control (WT) mice. $\boldsymbol{A}$, Pavlovian conditioning: entries into a food magazine increased during presentations of a stimulus associated with food delivery $(\mathrm{CS}+)$, but decreased during presentations of a stimulus associated with no outcome (CS-). B, Goal-tracking: magazine entries that occurred following $C S+$ onset, but before food delivery (that is, goal-tracking responses), significantly increased across conditioning sessions (main effect of session, $F_{(10,190)}=7.6, p<0.01$ ), but did not differ between genotypes (session $\times$ genotype interaction, $F_{(10,190)}=0.171, p>0.05$ ). C, Food self-administration for PIT cohort: both genotypes responded more on a lever that resulted in food delivery (Act), than an alternate lever on which responding had no consequence (Ina), when food delivery occurred under an FR1 (main effect of lever, $F_{(1,14)}=54.84, p<0.001$; lever $\times$ genotype interaction $\left.F_{(1,14)}=1.18, p>0.05\right)$ or a variable-interval $60 \mathrm{~s} s c h e d u l e(\mathrm{VI} 60)$ (main effect of lever $F_{(1,14)}=37.61, p<0.001$; lever $\times$ genotype $F_{(1,14)}=0.10, p>0.05$ ). D, PIT test: responses on a lever that previously led to the delivery of food significantly increased during $C S+$ presentations, compared with a decrease in responding during $C S$ - presentations (main effect of stimulus, $F_{(1,14)}=20.93, p<0.001$ ). There was no difference in PIT between genotypes (stimulus $\times$ genotype, $F_{(1,14)}=0.125, p>0.05$ ). Elevation score $=$ lever responses during $C S$ minus responses pre $C S$. $\boldsymbol{E}$, Conditioned reinforcement: both genotypes preferentially responded on a lever that led to $C S+$ presentations, compared with a $C S-$ paired lever (main effect of lever, $F_{(1,19)}=24.38, p<0.001$ ). However, KD mice made significantly fewer $C S+$ paired lever responses than WT mice (genotype $\times$ lever, $F_{(1,19)}=5.57, p<0.05$ ). ${ }^{*} p<0.05$, post hoc comparison between genotypes by $t$ test. $\boldsymbol{F}$, Sign-tracking: both genotypes preferentially approached the location of the $C S+$ during its presentations. However, KD mice made significantly fewer $C S+$ approaches than WT mice. ${ }^{\#} p<0.05$, comparison between genotypes by Wilcoxon matched pairs test.

which a conventional RNA-polymerase II promoter (the D1Rpromoter) drives the expression of artificial microRNAs and a reporter. A similar approach has been reported previously for interference with other genes in nurse cells (Rao et al., 2006) and, together with a very recent report (Garbett et al., 2010), our find- ings show that this technique can be used successfully in the brain. Compared with conditional gene deletion this approach has the advantage that it involves only one mouse line and offers the perspective to be used, in modified forms, in other organisms in which targeted mutagenesis is not feasible. Previous use of RNAi-based approaches have raised our awareness that excessive levels of short RNAs may oversaturate exportin 5 and thus block the processing of endogenous short RNAs leading to perturbed cellular homeostasis (Grimm et al., 2006). This is not the case for the mGluR5 ${ }^{\mathrm{KD}-\mathrm{D} 1}$ mice, where maturation of short RNAs is normal. Most likely, previously reported problems were caused by the use of tools resulting in very high levels of short RNAs, such as strong RNA polymerase III promoters or the use of shRNAs instead of artificial microRNAs (Boudreau et al., 2009). Another potential problem is off-target effects. Although we cannot completely exclude interference with the translation of other RNAs, we show that the levels of mRNAs with partial complementarity to the microRNAs are not affected. Collectively this suggests that artificial microRNAs driven by cell typespecific promoters will be a very useful addition to the neuroscience tool-box, greatly reducing the necessary size of transgenic animal colonies.

Using the cue-induced reinstatement model, considered an animal model of relapse vulnerability (Shaham et al., 2003; Sanchis-Segura and Spanagel, 2006; Stephens et al., 2010), our current findings add to previous reports indicating a role of mGluR5 in regulating behavioral responses to cocaine (Chiamulera et al., 2001) and cocaine-paired cues (Bäckström and Hyytiä, 2006) by suggesting a location of mGluR5 necessary for the cue-induced reinstatement of cocaine-seeking, while the primary reinforcing effects of cocaine are unaffected following specific knock-down of mGluR5 on D1R-expressing neurons. Our study also lends mechanistic confidence to previous reports that have used pharmacological tools to identify a role of mGluR5 in behaviors maintained by reward-paired stimuli (Tessari et al., 2004; Bespalov et al., 2005; Bäckström and Hyytiä, 2006; Schroeder et al., 2008; Gass et al., 2009; Kumaresan et al., 2009; MartinFardon et al., 2009; O'Connor et al., 2010), since these reports could have reflected off-target (Olive, 2009), anhedonic (Bäckström and Hyytiä, 2007) or reinforcing (van der Kam et al., 2009) effects of the pharmacological tools used.

Associative reward-learning, that attributes drug-paired stimuli with properties necessary for triggering relapse-like behaviors, 
is not a unitary process but can be dissociated psychologically, neurobiologically (Everitt et al., 2001) and genetically (Mead and Stephens, 2003a,b). Thus, to determine precisely which rewardlearning processes were disrupted in mutant mice, we used Pavlovian conditioning procedures in which a stimulus was paired with the delivery of food [that is, the unconditioned stimulus (US)]. A potential limitation of this approach is that the extent to which neural circuitries that mediate associative learning for natural reinforcers (such as food) overlap with those engaged by drug reinforcers is not fully understood. However, attempts to employ purely Pavlovian conditioning procedures using a "drug US" have been hampered by the negative behavioral effects associated with nonresponse contingent drug delivery (Dworkin et al., 1995; Mitchell et al., 1996; Arroyo et al., 1998). Nevertheless, our findings that cocaine-seeking and specific incentive learning processes were both impaired in mutant mice provide empirical support for multiple contemporary theories of drug addiction, which propose that the ability of drug-paired stimuli to influence drug-seeking and relapse reflect the interactions of addictive drugs with neural systems that normally subserve associative reward-learning processes for natural reinforcers (Stewart et al., 1984; Tiffany, 1990; Robinson and Berridge, 1993; Everitt et al., 2001; Stephens and Duka, 2008; Thomas et al., 2008).

An advantage of the behavioral models used in the present study is that the underlying neural circuitry is relatively well characterized. The nucleus accumbens is crucial for learning necessary for conditioned reinforcement (Parkinson et al., 1999; Ito et al., 2004), the development of sign-tracking responses (Parkinson et al., 2000; Di Ciano et al., 2001) and reinstatement of cocaine-seeking (Fuchs et al., 2004). This strongly suggests that the deficits in associative learning and reinstatement of cocaineseeking observed in the mGluR $5^{\mathrm{KD}-\mathrm{D} 1}$ mice are due to the lack of mGluR5 in D1-MSNs in the nucleus accumbens. Moreover, the continued expression of mGluR5 on non-D1 MSNs [that is, D2MSNs, except the minority expressing both D2R and D1R (Valjent et al., 2009)] was insufficient to support specific incentive learning processes and relapse-like behaviors in mutant mice. Although we cannot formally rule out the contribution of mGluR5 on MSNs in the dorsal striatum or in other D1Rexpressing cells, such as those in the hippocampus or cortex, a major contribution from mGluR5 in the latter structures seems unlikely since we saw no significant reduction of mGluR5 in the cortex or hippocampus of mGluR $5^{\mathrm{KD}-\mathrm{D} 1}$ mice. These observations may suggest that the D1R-promoter is less strong in these regions or that D1 and mGluR5 are not expressed in the same neuronal populations.

Recent reports have highlighted that stimulation of striatal D1R and NMDA receptors, and the resultant activation of extracellular signal-related kinase (ERK) specifically in D1 MSNs, represent critical mechanisms through which the long-term effects of addictive drugs are mediated (Heusner and Palmiter, 2005; Valjent et al., 2005; Bertran-Gonzalez et al., 2008). Moreover, both D1R and NMDA receptors in the accumbens appear critical for the early consolidation of appetitive Pavlovian memories (Dalley et al., 2005). These reports are particularly relevant in the context of our current findings, given the close interactions between mGluR5 and D1R (Paolillo et al., 1998; Voulalas et al., 2005; Schotanus and Chergui, 2008) and NMDA receptors (Pisani et al., 2001; Mao and Wang, 2002; Choe et al., 2006) in the striatum. Thus, it is possible that impaired incentive learning and relapse-like behaviors in mGluR $5^{\mathrm{KD}-\mathrm{D} 1}$ mice were due, in part, to changes in striatal D1R and NMDA receptor function as a consequence of mGluR5 loss. A future challenge will be to further understand the complex interplay of glutamate and dopamine signaling within striatal circuits, and determine precisely which cellular mechanisms encode appetitive memories and mediate subsequent behavioral responses to environmental stimuli associated with natural and drug reinforcers.

In summary, our present findings, together with a recent report from our laboratory (O'Connor et al., 2010), suggest that mGluR5-mediated neuroplastic events on D1-MSNs are crucial for the formation of psychologically distinct associations between environmental stimuli and rewards that endow reward-paired stimuli with the subsequent ability to both reinforce and attract motivated behaviors. Furthermore, recent reports have revealed that mGluR5-mediated striatal plasticity is involved in, or affected by, cocaine experience (Fourgeaud et al., 2004; Moussawi et al., 2009). Our report provides a psychobiological context for these findings by pointing to glutamate signaling at mGluR5 on striatal D1-MSNs as a key mediator through which repeated cocaine experience (and presumably exposure to other drugs of abuse) produces a persistent increase in the susceptibility to relapse triggered by environmental stimuli associated with drug use.

\section{References}

Anderson SM, Pierce RC (2005) Cocaine-induced alterations in dopamine receptor signaling: implications for reinforcement and reinstatement. Pharmacol Ther 106:389-403.

Anwyl R (2009) Metabotropic glutamate receptor-dependent long-term potentiation. Neuropharmacology 56:735-740.

Arroyo M, Markou A, Robbins TW, Everitt BJ (1998) Acquisition, maintenance and reinstatement of intravenous cocaine self-administration under a second-order schedule of reinforcement in rats: effects of conditioned cues and continuous access to cocaine. Psychopharmacology (Berl) 140:331-344.

Bäckström P, Hyytiä P (2006) Ionotropic and metabotropic glutamate receptor antagonism attenuates cue-induced cocaine seeking. Neuropsychopharmacology 31:778-786.

Bäckström P, Hyytiä P (2007) Involvement of AMPA/kainate, NMDA, and mGlu5 receptors in the nucleus accumbens core in cue-induced reinstatement of cocaine seeking in rats. Psychopharmacology (Berl) 192:571-580.

Bellone C, Lüscher C, Mameli M (2008) Mechanisms of synaptic depression triggered by metabotropic glutamate receptors. Cell Mol Life Sci 65:2913-2923.

Berke JD, Hyman SE (2000) Addiction, dopamine, and the molecular mechanisms of memory. Neuron 25:515-532.

Bertran-Gonzalez J, Bosch C, Maroteaux M, Matamales M, Hervé D, Valjent E, Girault JA (2008) Opposing patterns of signaling activation in dopamine D1 and D2 receptor-expressing striatal neurons in response to cocaine and haloperidol. J Neurosci 28:5671-5685.

Bespalov AY, Dravolina OA, Sukhanov I, Zakharova E, Blokhina E, Zvartau E, Danysz W, van Heeke G, Markou A (2005) Metabotropic glutamate receptor (mGluR5) antagonist MPEP attenuated cue- and scheduleinduced reinstatement of nicotine self-administration behavior in rats. Neuropharmacology 49 [Suppl 1]:167-178.

Boudreau RL, Martins I, Davidson BL (2009) Artificial microRNAs as siRNA shuttles: improved safety as compared to shRNAs in vitro and in vivo. Mol Ther 17:169-175.

Chiamulera C, Epping-Jordan MP, Zocchi A, Marcon C, Cottiny C, Tacconi S, Corsi M, Orzi F, Conquet F (2001) Reinforcing and locomotor stimulant effects of cocaine are absent in mGluR5 null mutant mice. Nat Neurosci 4:873-874.

Choe ES, Shin EH, Wang JQ (2006) Regulation of phosphorylation of NMDA receptor NR1 subunits in the rat neostriatum by group I metabotropic glutamate receptors in vivo. Neurosci Lett 394:246-251.

Crombag HS, Galarce EM, Holland PC (2008) Pavlovian influences on goal-directed behavior in mice: the role of cue-reinforcer relations. Learn Mem 15:299-303.

Dalley JW, Lääne K, Theobald DE, Armstrong HC, Corlett PR, Chudasama Y, Robbins TW (2005) Time-limited modulation of appetitive Pavlovian 
memory by $\mathrm{D} 1$ and NMDA receptors in the nucleus accumbens. Proc Natl Acad Sci U S A 102:6189-6194.

Di Ciano P, Cardinal RN, Cowell RA, Little SJ, Everitt BJ (2001) Differential involvement of NMDA, AMPA/kainate, and dopamine receptors in the nucleus accumbens core in the acquisition and performance of pavlovian approach behavior. J Neurosci 21:9471-9477.

Dworkin SI, Mirkis S, Smith JE (1995) Response-dependent versus response-independent presentation of cocaine: differences in the lethal effects of the drug. Psychopharmacology (Berl) 117:262-266.

Everitt BJ, Robbins TW (2005) Neural systems of reinforcement for drug addiction: from actions to habits to compulsion. Nat Neurosci 8:1481-1489.

Everitt BJ, Dickinson A, Robbins TW (2001) The neuropsychological basis of addictive behaviour. Brain Res Brain Res Rev 36:129-138.

Fourgeaud L, Mato S, Bouchet D, Hémar A, Worley PF, Manzoni OJ (2004) A single in vivo exposure to cocaine abolishes endocannabinoidmediated long-term depression in the nucleus accumbens. J Neurosci 24:6939-6945.

Fuchs RA, Evans KA, Parker MC, See RE (2004) Differential involvement of the core and shell subregions of the nucleus accumbens in conditioned cue-induced reinstatement of cocaine seeking in rats. Psychopharmacology (Berl) 176:459-465.

Garbett KA, Horvath S, Ebert PJ, Schmidt MJ, Lwin K, Mitchell A, Levitt P, Mirnics K (2010) Novel animal models for studying complex brain disorders: BAC-driven miRNA-mediated in vivo silencing of gene expression. Mol Psychiatry. Advance online publication. Retrieved March 1, 2010. doi:10.1038/mp.2010.1.

Gass JT, Osborne MP, Watson NL, Brown JL, Olive MF (2009) mGluR5 antagonism attenuates methamphetamine reinforcement and prevents reinstatement of methamphetamine-seeking behavior in rats. Neuropsychopharmacology 34:820-833.

Gerfen CR, Engber TM, Mahan LC, Susel Z, Chase TN, Monsma FJ Jr, Sibley DR (1990) D1 and D2 dopamine receptor-regulated gene expression of striatonigral and striatopallidal neurons. Science 250:1429-1432.

Goto Y, Grace AA (2008) Limbic and cortical information processing in the nucleus accumbens. Trends Neurosci 31:552-558.

Grimm D, Streetz KL, Jopling CL, Storm TA, Pandey K, Davis CR, Marion P, Salazar F, Kay MA (2006) Fatality in mice due to oversaturation of cellular microRNA/short hairpin RNA pathways. Nature 441:537-541.

Gubellini P, Saulle E, Centonze D, Costa C, Tropepi D, Bernardi G, Conquet F, Calabresi P (2003) Corticostriatal LTP requires combined mGluR1 and mGluR5 activation. Neuropharmacology 44:8-16.

Heiman M, Schaefer A, Gong S, Peterson JD, Day M, Ramsey KE, SuárezFariñas M, Schwarz C, Stephan DA, Surmeier DJ, Greengard P, Heintz N (2008) A translational profiling approach for the molecular characterization of CNS cell types. Cell 135:738-748.

Heusner CL, Palmiter RD (2005) Expression of mutant NMDA receptors in dopamine D1 receptor-containing cells prevents cocaine sensitization and decreases cocaine preference. J Neurosci 25:6651-6657.

Hyman SE, Malenka RC, Nestler EJ (2006) Neural mechanisms of addiction: the role of reward-related learning and memory. Annu Rev Neurosci 29:565-598.

Ito R, Robbins TW, Everitt BJ (2004) Differential control over cocaineseeking behavior by nucleus accumbens core and shell. Nat Neurosci 7:389-397.

Kauer JA, Malenka RC (2007) Synaptic plasticity and addiction. Nat Rev Neurosci 8:844-858.

Kourrich S, Rothwell PE, Klug JR, Thomas MJ (2007) Cocaine experience controls bidirectional synaptic plasticity in the nucleus accumbens. J Neurosci 27:7921-7928.

Kumaresan V, Yuan M, Yee J, Famous KR, Anderson SM, Schmidt HD, Pierce RC (2009) Metabotropic glutamate receptor 5 (mGluR5) antagonists attenuate cocaine priming- and cue-induced reinstatement of cocaine seeking. Behav Brain Res 202:238-244.

Malenka RC, Bear MF (2004) LTP and LTD: an embarrassment of riches. Neuron 44:5-21.

Mameli M, Halbout B, Creton C, Engblom D, Parkitna JR, Spanagel R, Lüscher C (2009) Cocaine-evoked synaptic plasticity: persistence in the VTA triggers adaptations in the NAc. Nat Neurosci 12:1036-1041.

Mao L, Wang JQ (2002) Glutamate cascade to cAMP response elementbinding protein phosphorylation in cultured striatal neurons through calcium-coupled group I metabotropic glutamate receptors. Mol Pharmacol 62:473-484.
Martin M, Chen BT, Hopf FW, Bowers MS, Bonci A (2006) Cocaine selfadministration selectively abolishes LTD in the core of the nucleus accumbens. Nat Neurosci 9:868-869.

Martin-Fardon R, Baptista MA, Dayas CV, Weiss F (2009) Dissociation of the effects of MTEP [3-[(2-methyl-1,3-thiazol-4-yl)ethynyl]piperidine] on conditioned reinstatement and reinforcement: comparison between cocaine and a conventional reinforcer. J Pharmacol Exp Ther 329: $1084-1090$.

Mead AN, Stephens DN (2003a) Selective disruption of stimulus-reward learning in glutamate receptor grial knock-out mice. J Neurosci 23:1041-1048.

Mead AN, Stephens DN (2003b) Involvement of AMPA receptor GluR2 subunits in stimulus-reward learning: evidence from glutamate receptor gria2 knock-out mice. J Neurosci 23:9500-9507.

Mitchell SH, Laurent CL, de Wit H (1996) Interaction of expectancy and the pharmacological effects of $d$-amphetamine: subjective effects and selfadministration. Psychopharmacology (Berl) 125:371-378.

Moussawi K, Pacchioni A, Moran M, Olive MF, Gass JT, Lavin A, Kalivas PW (2009) N-Acetylcysteine reverses cocaine-induced metaplasticity. Nat Neurosci 12:182-189.

O'Connor EC, Crombag HS, Mead AN, Stephens DN (2010) The mGluR5 antagonist MTEP dissociates the acquisition of predictive and incentive motivational properties of reward-paired stimuli in mice. Neuropsychopharmacology 35:1807-1817.

Olive MF (2009) Metabotropic glutamate receptor ligands as potential therapeutics for addiction. Curr Drug Abuse Rev 2:83-989.

Paolillo M, Montecucco A, Zanassi P, Schinelli S (1998) Potentiation of dopamine-induced cAMP formation by group I metabotropic glutamate receptors via protein kinase $\mathrm{C}$ in cultured striatal neurons. Eur J Neurosci 10:1937-1945.

Parkinson JA, Olmstead MC, Burns LH, Robbins TW, Everitt BJ (1999) Dissociation in effects of lesions of the nucleus accumbens core and shell on appetitive pavlovian approach behavior and the potentiation of conditioned reinforcement and locomotor activity by D-amphetamine. J Neurosci 19:2401-2411.

Parkinson JA, Willoughby PJ, Robbins TW, Everitt BJ (2000) Disconnection of the anterior cingulate cortex and nucleus accumbens core impairs Pavlovian approach behavior: further evidence for limbic cortical-ventral striatopallidal systems. Behav Neurosci 114:42-63.

Parkitna JR, Engblom D, Schütz G (2009) Generation of Cre recombinaseexpressing transgenic mice using bacterial artificial chromosomes. Methods Mol Biol 530:325-342.

Pisani A, Gubellini P, Bonsi P, Conquet F, Picconi B, Centonze D, Bernardi G, Calabresi P (2001) Metabotropic glutamate receptor 5 mediates the potentiation of $\mathrm{N}$-methyl-D-aspartate responses in medium spiny striatal neurons. Neuroscience 106:579-587.

Rao MK, Pham J, Imam JS, MacLean JA, Murali D, Furuta Y, Sinha-Hikim AP, Wilkinson MF (2006) Tissue-specific RNAi reveals that WT1 expression in nurse cells controls germ cell survival and spermatogenesis. Genes Dev 20:147-152.

Rescorla RA (1988) Pavlovian conditioning. It's not what you think it is. Am Psychol 43:151-160.

Robinson TE, Berridge KC (1993) The neural basis of drug craving: an incentive-sensitization theory of addiction. Brain Res Brain Res Rev 18:247-291.

Robinson TE, Flagel SB (2009) Dissociating the predictive and incentive motivational properties of reward-related cues through the study of individual differences. Biol Psychiatry 65:869-873.

Sanchis-Segura C, Spanagel R (2006) Behavioural assessment of drug reinforcement and addictive features in rodents: an overview. Addict Biol 11:2-38.

Schotanus SM, Chergui K (2008) Dopamine D1 receptors and group I metabotropic glutamate receptors contribute to the induction of long-term potentiation in the nucleus accumbens. Neuropharmacology 54:837-844.

Schroeder JP, Spanos M, Stevenson JR, Besheer J, Salling M, Hodge CW (2008) Cue-induced reinstatement of alcohol-seeking behavior is associated with increased ERK1/2 phosphorylation in specific limbic brain regions: blockade by the mGluR5 antagonist MPEP. Neuropharmacology 55:546-554.

Shaham Y, Shalev U, Lu L, De Wit H, Stewart J (2003) The reinstatement model of drug relapse: history, methodology and major findings. Psychopharmacology (Berl) 168:3-20. 
Stephens DN, Duka T (2008) Review. Cognitive and emotional consequences of binge drinking: role of amygdala and prefrontal cortex. Philos Trans R Soc Lond B Biol Sci 363:3169-3179.

Stephens DN, Duka T, Crombag HS, Cunningham CL, Heilig M, Crabbe JC (2010) Reward sensitivity: issues of measurement, and achieving consilience between human and animal phenotypes. Addict Biol 15:145-168.

Stewart J, de Wit H, Eikelboom R (1984) Role of unconditioned and conditioned drug effects in the self-administration of opiates and stimulants. Psychol Rev 91:251-268.

Sung KW, Choi S, Lovinger DM (2001) Activation of group I mGluRs is necessary for induction of long-term depression at striatal synapses. J Neurophysiol 86:2405-2412.

Tallaksen-Greene SJ, Kaatz KW, Romano C, Albin RL (1998) Localization of mGluRla-like immunoreactivity and mGluR5-like immunoreactivity in identified populations of striatal neurons. Brain Res 780:210-217.

Tessari M, Pilla M, Andreoli M, Hutcheson DM, Heidbreder CA (2004) Antagonism at metabotropic glutamate 5 receptors inhibits nicotine- and cocaine-taking behaviours and prevents nicotine-triggered relapse to nicotine-seeking. Eur J Pharmacol 499:121-133.

Thomas MJ, Kalivas PW, Shaham Y (2008) Neuroplasticity in the mesolimbic dopamine system and cocaine addiction. Br J Pharmacol 154:327-342.
Tiffany ST (1990) A cognitive model of drug urges and drug-use behavior: role of automatic and nonautomatic processes. Psychol Rev 97:147-168.

Tomie A, Grimes KL, Pohorecky LA (2008) Behavioral characteristics and neurobiological substrates shared by Pavlovian sign-tracking and drug abuse. Brain Res Rev 58:121-135.

Valjent E, Pascoli V, Svenningsson P, Paul S, Enslen H, Corvol JC, Stipanovich A, Caboche J, Lombroso PJ, Nairn AC, Greengard P, Hervé D, Girault JA (2005) Regulation of a protein phosphatase cascade allows convergent dopamine and glutamate signals to activate ERK in the striatum. Proc Natl Acad Sci U S A 102:491-496.

Valjent E, Bertran-Gonzalez J, Hervé D, Fisone G, Girault JA (2009) Looking BAC at striatal signaling: cell-specific analysis in new transgenic mice. Trends Neurosci 32:538-547.

van der Kam EL, De Vry J, Tzschentke TM (2009) The mGlu5 receptor antagonist 2-methyl-6-(phenylethynyl)pyridine (MPEP) supports intravenous self-administration and induces conditioned place preference in the rat. Eur J Pharmacol 607:114-120.

Voulalas PJ, Holtzclaw L, Wolstenholme J, Russell JT, Hyman SE (2005) Metabotropic glutamate receptors and dopamine receptors cooperate to enhance extracellular signal-regulated kinase phosphorylation in striatal neurons. J Neurosci 25:3763-3773. 